\title{
Testicular vein syndrome: one of the first described case of robotic assisted treatment
}

Nilo Jorge Barreto 1, Leonardo Marques Calazans 2, Francisco Carlos Lustiago Júnior 3, ', Arthur Eugênio C. Bisinotto 4, João Paulo Barbosa 5

1 Preceptor of the Urology Residency of the Obras Sociais Irmã Dulce, Bahia, Ba, Brazil.

2 Head of the Urology service of Obras Sociais Irmã Dulce, Bahia, Ba, Brazil.

3 Resident in Urology doctor of Obras Sociais Irmã Dulce, Bahia, Ba, Brazil.

4 Fellowship doctor of Urology of Obras Sociais Irmã Dulce, Bahia, Ba, Brazil.

5 Urologist at the Albert Einstein hospital, Goiania, Go, Brazil.

*Corresponding author: Francisco Carlos Lustiago Júnior. Street Aristides Fraga Lima, $n 385^{\circ}$ - District Pituba. Zip Code: 40301-155 -Bahia, Ba, Brazil. Phone: +55 (74) 991261416 E-mail: Fclustiago@gmail.com.

Research Ethics Committee Approval (if necessary): We declare that the patient approved the study by signing an informed consent form and the study followed the ethical guidelines established by the Declaration of Helsinki.

Received on: Nov 21, 2021. Accepted on: Nov 30, 2021. Available online: Jan 5, 2022.
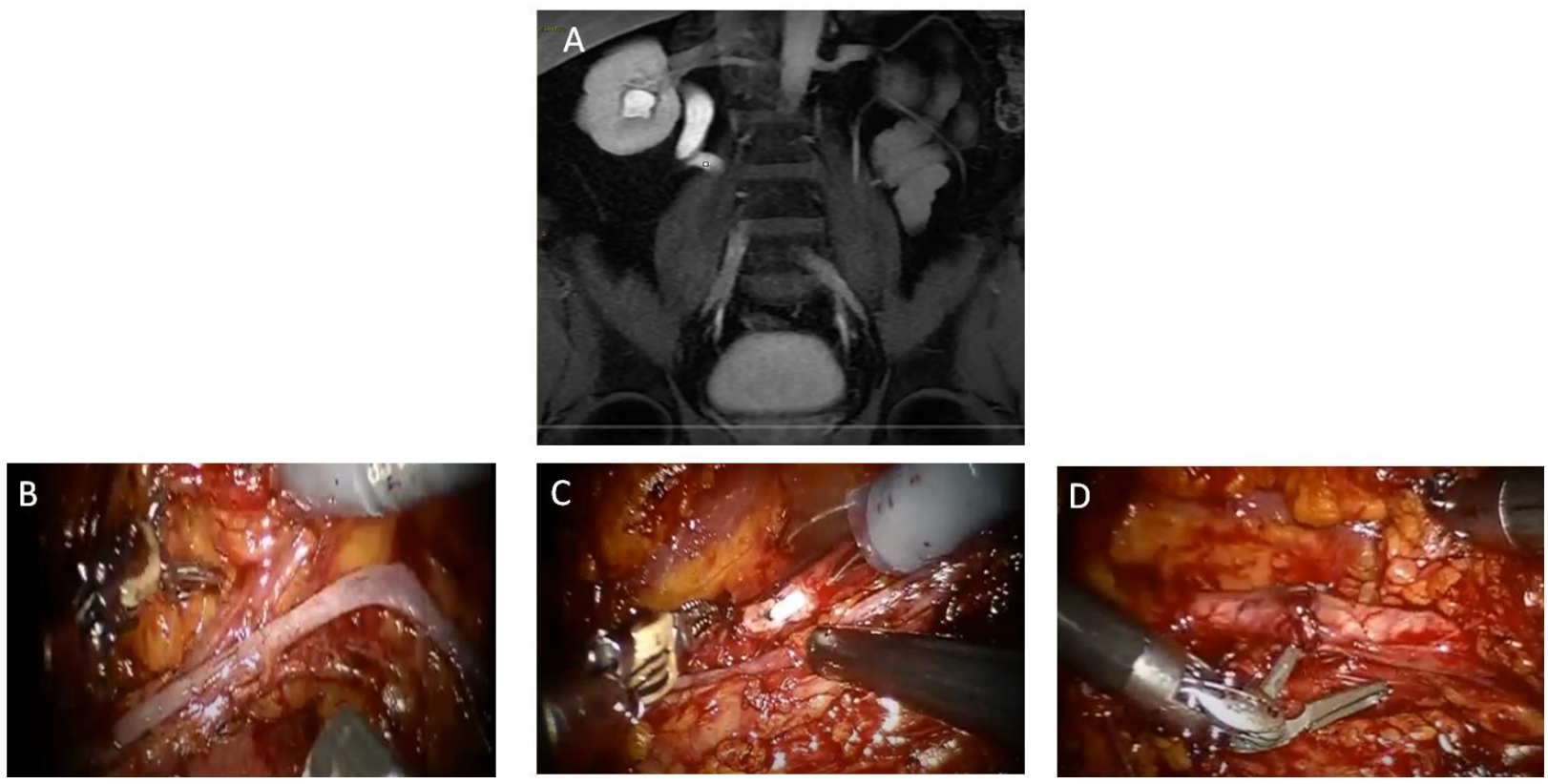

Figure 1. A. Abdominal contrast tomography scan, that demonstrated hydronephrosis and focal thickening of the right ureter. B. a) gonadal vein and b) artery that transited above the C- ureter. C. The stenotic segment of the ureter. D. Uretero-ureteral anastomosis.

The testicular vein syndrome

obstruction, resulting in (TVS) is a rare cause of ureteral ureterohydronephrosis [1]. The cause of 
obstruction is an extrinsic compression of the ureter in the intersection of the ipsilateral gonadal vein [1]. The first case of TVS found in literature was reported in 1975 [2]. This is the $9^{\text {th }}$ case described and the first one treated by robotic assisted surgery. The objective of this paper is to describe a rare pathology with video presentation of the surgery technique used, robot assisted surgery.

A 58-year-old male presented with a 5 years history of colicky lumbar pain, with progressive worsening in the last months and a single episode of gross hematuria. He had well controlled hypertension and no previous surgery. He never had history of urinary calculi.

First exam performed was an abdominal contrast tomography (CT) scan, that demonstrated hydronephrosis and focal thickening of the right ureter (Figure 1A). Posteriorly, magnetic resonance imaging (MRI) of the urinary tract was performed, with the founding of ureteral stricture of $2,0 \mathrm{~cm}$ just posterior to the testicular vein intersection. This stricture was $5,5 \mathrm{~cm}$ distal from ureteropelvic junction and was associated with moderate collecting system dilatation.

Due to the suspicion of TVS, ureteroscopy and pyelogram were performed, with the founding of a luminal stenosis of approximately $90 \%$. A ureteral stent was placed. Opted for transperitoneal robotic assisted laparoscopic approach with identification of gonadal vein and artery that transited above the ureter (Figure 1B).

Vessel ligation was performed as well as resection of the stenotic segment of the ureter (Figure 1C). An ureteroureteral anastomosis was performed with separated 5-0 Polydioxanone sutures (Figure 1D). The patient was discharged after 2 days of surgery, with no urinary catheter or drain.

TVS is a rare and challenging diagnosis. This case demonstrates that the robotic approach facilitates ureter anastomosis and permits faster recuperation.

\section{References}

[1] Hamidi H. Testicular vein syndrome: Review of the literature and recent case report. The Egyptian Journal of Radiology and Nuclear Medicine. 2017 Dec.; 48(4):1125-1130. doi: 10.1016/j.ejrnm.2017.08.012.

[2] Arvind NK, Singh O, Gupta SS. Testicular vein syndrome and its treatment with a laparoscopic approach. JSLS. 2011 Oct-Dec;15(4):580-4. doi: 10.4293/108680811X13176785204797.

Conflict of interest: The author declares no conflicts of interest.

Acknowledgements: None.

Funding: None.

How to cite this article: Barreto NJ, Calazans LM, Lustiago Júnior FC, Bisinotto AEC, Barbosa JP. Testicular vein syndrome: one of the first 
described case of robotic assisted

treatment. Brazilian Journal of Case

Reports. 2022 Jan-Mar;02(1):21-23. 